\title{
$\Delta$ FosB Induction in Orbitofrontal Cortex Mediates Tolerance to Cocaine-Induced Cognitive Dysfunction
}

\author{
Catharine A. Winstanley, ${ }^{1}$ Quincey LaPlant, ${ }^{1}$ David E. H. Theobald, ${ }^{1}$ Thomas A. Green, ${ }^{1}$ Ryan K. Bachtell, ${ }^{1}$ \\ Linda I. Perrotti, ${ }^{1}$ Ralph J. DiLeone, ${ }^{1}$ Scott J. Russo, ${ }^{1}$ William J. Garth, ${ }^{2}$ David W. Self, ${ }^{1}$ and Eric J. Nestler ${ }^{1}$ \\ ${ }^{1}$ Departments of Psychiatry and Basic Neuroscience and ${ }^{2}$ Charles River Laboratories CSS, The University of Texas Southwestern Medical Center, Dallas, \\ Texas 75390
}

Current cocaine users show little evidence of cognitive impairment and may perform better when using cocaine, yet withdrawal from prolonged cocaine use unmasks dramatic cognitive deficits. It has been suggested that such impairments arise in part through druginduced dysfunction within the orbitofrontal cortex $(\mathrm{OFC})$, yet the neurobiological mechanisms remain unknown. We observed that chronic cocaine self-administration increased expression of the transcription factor $\Delta$ FosB within both medial and orbitofrontal regions of the rat prefrontal cortex. However, the increase in OFC $\Delta$ FosB levels was more pronounced after self-administered rather than experimenter-administered cocaine, a pattern that was not observed in other regions. We then used rodent tests of attention and decision making to determine whether $\Delta \mathrm{FosB}$ within the $\mathrm{OFC}$ contributes to drug-induced alterations in cognition. Chronic cocaine treatment produced tolerance to the cognitive impairments caused by acute cocaine. Overexpression of a dominant-negative antagonist of $\Delta \mathrm{FosB}$, $\Delta$ JunD, in the OFC prevented this behavioral adaptation, whereas locally overexpressing $\Delta$ FosB mimicked the effects of chronic cocaine. Gene microarray analyses identified potential molecular mechanisms underlying this behavioral change, including an increase in transcription of metabotropic glutamate receptor subunit 5 and $\mathrm{GABA}_{\mathrm{A}}$ receptors as well as substance P. Identification of $\triangle \mathrm{FosB}$ in the OFC as a mediator of tolerance to the effects of cocaine on cognition provides fundamentally new insight into the transcriptional modifications associated with addiction.

Key words: orbitofrontal cortex; addiction; impulsivity; five-choice serial reaction time task; delay-discounting; gene microarray

\section{Introduction}

Although much research to date has focused on understanding the reinforcing effects of addictive drugs (Everitt and Robbins, 2005), recent evidence indicates that cognitive changes caused by repeated drug intake are also important in the generation and maintenance of addiction and may determine whether therapy is successful (Jentsch and Taylor, 1999; Rogers and Robbins, 2001; Kalivas and Volkow, 2005). Withdrawal from long-term drug use is associated with deficient performance on a range of neuropsychological tests suggestive of impaired attention, memory, executive function, and impulse control (Rogers and Robbins, 2001). Some of these effects have been replicated in animal models (Dalley et al., 2005a). Abstinent cocaine users show hypofunction within the orbitofrontal cortex (OFC) (Volkow and Fowler, 2000), a key brain region implicated in regulating goal-directed

\footnotetext{
Received June 6, 2007; revised Aug. 11, 2007; accepted Aug. 11, 2007.

This work was supported by grants from the National Institute on Drug Abuse and the National Institute of Mental Health (E.J.N., D.W.S.).

Correspondence should be addressed to Eric J. Nestler, Department of Psychiatry, The University of Texas Southwestern Medical Center, 5323 Harry Hines Boulevard, Dallas, TX 75390-9070. E-mail: eric.nestler@ utsouthwestern.edu.

C. A. Winstanley's present address: Department of Psychology, University of British Columbia, 2136 West Mall, Vancouver, British Columbia, Canada V6T 124

R.J. DiLeone's present address: Department of Psychiatry, Yale University School of Medicine, 34 Park Street, New Haven, СT 06508

D0I:10.1523/JNEUROSCI.2566-07.2007

Copyright $\odot 2007$ Society for Neuroscience $\quad$ 0270-6474/07/2710497-11\$15.00/0
}

behavior and impulsivity (Krawczyk, 2002). Cognitive deficits associated with withdrawal from long-term cocaine use have been attributed to OFC dysfunction (Schoenbaum et al., 2006). However, recent findings indicate that the cognitive abilities of cocaine addicts are either improved or unaffected by acute cocaine (Hopper et al., 2004; Johnson et al., 2005), and data from preclinical studies indicate that chronic amphetamine intake reduces the impulsive responding caused by an acute dose of the drug (Dalley et al., 2005b). Chronic psychostimulant exposure therefore appears to reduce the susceptibility of individuals to the cognitive dysfunction caused by the drug, yet this tolerance is accompanied by impairments in cognition after cessation of drug use. These data suggest that repeated cocaine exposure affects cognition in a manner integral to the addicted state and implicates the OFC as one brain region possibly involved, yet little is known about the underlying molecular mechanisms.

The persistence of addiction indicates that changes in gene transcription are involved, partly mediated by the transcription factor $\Delta$ FosB, a truncated product of the fos $B$ gene (Nestler et al., 2001). $\Delta$ FosB preferentially heterodimerizes with JunD to form activator protein-1 (AP-1) complexes, which regulate transcription at AP-1 sites in responsive genes. Unlike other Fos family members that are induced rapidly but transiently by addictive drugs, $\Delta$ FosB accumulates in brain after chronic drug exposure and persists for long periods attributable to its unusual stability (Nestler et al., 2001). $\Delta$ FosB induction is most pronounced in 
areas implicated in regulating drug reward such as the nucleus accumbens, in which it enhances sensitivity to the rewarding and locomotor-activating effects of cocaine and morphine (Kelz et al., 1999; Colby et al., 2003; Zachariou et al., 2006). Although preliminary evidence suggests that chronic cocaine may induce $\Delta$ FosB in rat frontal cortex (Nye et al., 1995), the significance of this cortical expression has remained unexplored.

The aim of the current study was therefore to better characterize $\Delta$ FosB induction by cocaine in frontocortical regions and to understand its function. We used viral-mediated gene transfer to overexpress $\Delta$ FosB or its dominant-negative antagonist $\Delta$ JunD selectively within the OFC and used operant conditioning paradigms sensitive to OFC damage (Chudasama et al., 2003; Winstanley et al., 2004) and gene microarrays to characterize the functional role of $\Delta$ FosB in this brain region.

\section{Materials and Methods}

All experiments were performed in strict accordance with the National Institutes of Health Guide for the Care and Use of Laboratory Animals and were approved by the Institutional Animal Care and Use Committee at University of Texas Southwestern.

Animals. Animals were housed in pairs under a reverse light cycle (lights on from 9:00 P.M. to 9:00 A.M.) in a climate-controlled colony room. Brain tissue for the immunohistochemistry experiments was generated using male Sprague Dawley rats (self-administration, $n=16$; intraperitoneal cocaine plus saline injections, $n=6$ and 6; initial weight, 300-320 g; Charles River Laboratories, Kingston, NY). These animals had access to both food and water ad libitum. Subjects for the operant behavioral studies were male Long-Evans rats $(n=84$; initial weight, 300-320 g; Charles River Laboratories). Animals were food restricted to $85 \%$ of their free-feeding weight and maintained on $14 \mathrm{~g}$ of rat chow per day. Water was available ad libitum. Behavioral testing took place between 9:00 A.M. and 7:00 P.M. 5 d/week.

Cocaine self-administration. Rats were implanted with intrajugular catheters under surgical anesthesia [ketamine (Ketaset, $100 \mathrm{mg} / \mathrm{kg}$, i.m. injection) and xylazine (10 mg/kg, i.m); both drugs from Henry Schein, Melville, NY] and trained to self-administer either cocaine $(0.5 \mathrm{mg} / \mathrm{kg}$ per infusion, $n=6$ ) or saline $(n=6)$ under a fixed ratio 1 (FR1) schedule of reinforcement for 3 weeks in daily $4 \mathrm{~h}$ sessions as described previously (Bachtell et al., 2005). During the final week, animals achieved stable levels of self-administration, receiving an average of $98.92 \pm 10.26 \mathrm{infu}-$ sions of cocaine $\left(49.46 \pm 5.13 \mathrm{mg} \cdot \mathrm{kg}^{-1} \cdot \mathrm{d}^{-1}\right)$ or $20.93 \pm 3.18 \mathrm{infu}-$ sions of saline per session. Animals in a third group $(n=4)$ were yoked to an animal in the cocaine self-administration group so that a passive infusion of cocaine was delivered every time their self-administering partner responded for cocaine.

Sucrose self-administration. Animals were food restricted to $85 \%$ of their body weight to prevent weight gain and maintain stable operant responding for sucrose pellets. Animals were trained to lever press for sucrose pellets on an FR1 schedule of reinforcement in operant boxes equipped with two levers and a house light that was illuminated when contingent reinforcement was available. Responding on both levers was recorded, but only responding at the "active" lever resulted in pellet delivery. Each pellet delivery was followed by a $15 \mathrm{~s} \mathrm{timeout} \mathrm{period} \mathrm{when}$ the house light was turned off and lever presses had no scheduled consequence. Each session was terminated when the animal acquired 100 pellets.

Experimental design for cognitive behavioral testing. The timeline of this experiment is provided in Figure 1, and schematics for the behavioral tasks are summarized in supplemental Figure S1 (available at www.jneurosci.org as supplemental material). To study the functional consequences of $\triangle$ FosB induction in the OFC, we used two behavioral paradigms that assess cognitive performance. One cohort of rats learned the five-choice serial reaction time task (5CSRT) (Carli et al., 1983) in which animals respond at one of five spatially distinct holes only when a light inside is briefly illuminated. This paradigm measures numerous aspects of cognitive function affected by cocaine, including attention, motiva-

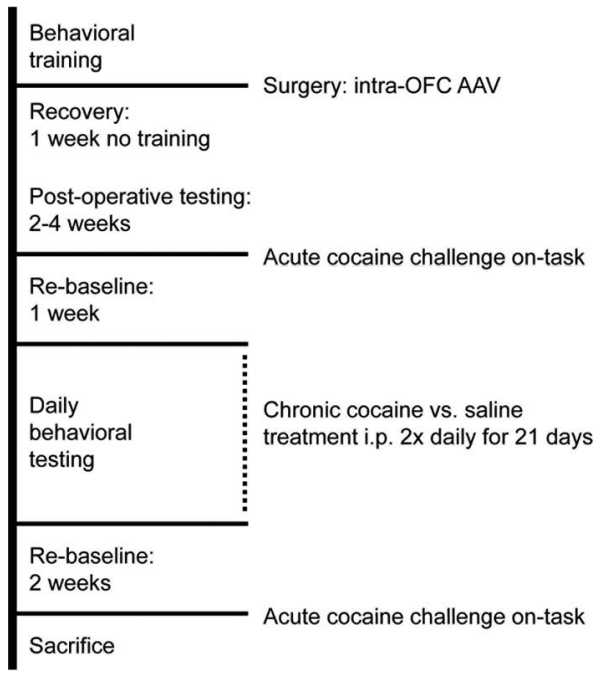

Figure 1. Timeline of the experimental design. Once animals had been trained, they were matching into groups based on their baseline performance and received intra-OFC infusions of AAVs designed to overexpress GFP, $\Delta \mathrm{FosB}$, or $\Delta$ JunD. Once stable postoperative performance had been established, animals were challenged with an acute cocaine dose on task. One week later, the chronic dosing regimen began. Animals received twice daily intraperitoneal injections of either saline or cocaine $(15 \mathrm{mg} / \mathrm{kg})$ in their home cages. Injections were given at least $2 \mathrm{~h}$ on either side of the behavioral test session. Behavioral testing continued daily during this time. Two weeks after the end of the chronic treatment, animals were again challenged with an acute dose of cocaine on task.

tion, and the tendency to respond prematurely or impulsively (i.e., before the light is turned on). A second cohort of rats learned a delaydiscounting paradigm (Evenden and Ryan, 1996) in which animals choose between a small immediate reward (one pellet) versus a larger delayed reward (four pellets). This measures another aspect of impulsivity that arises through aberrant decision making as opposed to behavioral disinhibition and that is also affected by psychostimulants. Both paradigms model neuropsychological tests used by clinicians and are sensitive to OFC damage (Chudasama et al., 2003; Winstanley et al., 2004). Details of the training procedures and testing equipment have been provided in previous reports (Chudasama et al., 2003; Winstanley et al., 2004) and are also available in supplemental data (available at www.jneurosci.org as supplemental material).

Once animals had achieved stable levels of performance on either the 5CSRT $(n=37)$ or the delay-discounting paradigm $(n=48)$, they were divided into three groups matched for baseline performance. An adenoassociated virus (AAV-2) overexpressing $\Delta$ FosB (Zachariou et al., 2006) (for details of AAV preparation, see Hommel et al., 2003) was infused selectively into the OFC of one group using standard stereotaxic surgical techniques (for details, see supplemental data, available at www.jneurosci.org as supplemental material), thereby mimicking induction of the protein by chronic cocaine. A second group received intra-OFC infusions of AAV- $\Delta$ JunD. AAV-green fluorescent protein (GFP) was used for the control group. For the 5CSRT experiment, animals were divided into two groups of $12(\Delta$ FosB and $\Delta$ JunD) and one group of 13 (GFP) and tested concurrently. For the delay-discounting experiment, two sets of 24 animals were run in series. Each set was divided into two groups $(n=12)$ and received either AAV-GFP or AAV- $\Delta \mathrm{JunD}$ (first set) or either AAV-GFP or AAV- $\triangle$ FosB (second set).

Postoperative performance was assessed until stable behavior had been established (5CSRT, 4 weeks; delay-discounting, 2 weeks). The effects of acute cocaine on task performance were then determined. Cocaine $\mathrm{HCl}$ was dissolved in $0.9 \%$ saline in a volume of $1 \mathrm{ml} / \mathrm{kg}$ and administered according to a Latin square drug design at the following doses: 5CSRT, 0, 5, 10, and $20 \mathrm{mg} / \mathrm{kg}$; delay-discounting paradigm, 0, 7.5, 15 , and $30 \mathrm{mg} / \mathrm{kg}$. Data from the highest dose used $(30 \mathrm{mg} / \mathrm{kg}$ ) were omitted from the analysis because animals did not perform the behavioral task as a result of increased stereotypy. Animals received injections 
of drug on Tuesday and Friday and were tested without drug on Monday and Thursday.

All animals were then tested for 1 week to ensure that drug exposure had not permanently affected behavior. To assess whether chronic administration of cocaine alters the cognitive effects of an acute cocaine exposure, animals were then matched both within and between their surgery groups into two equal sets. One group was treated chronically with saline and the other with cocaine $(15 \mathrm{mg} / \mathrm{kg}$, i.p.) for $21 \mathrm{~d}$. Behavioral testing continued Monday through Friday during this phase of the experiment. Injections were given at last $8 \mathrm{~h}$ apart and at least $2 \mathrm{~h}$ before and after the cessation of the behavioral test session so that animals were not performing the tasks under the influence of cocaine. We used intraperitoneal injections of cocaine in these experiments and not selfadministered cocaine, because intraperitoneal injections significantly increase $\Delta \mathrm{FosB}$ expression in the OFC but do so to a moderate degree, which allows for potential enhancement or blockade of its effects on overexpression of $\Delta \mathrm{FosB}$ or $\Delta \mathrm{JunD}$, respectively. Animals were then tested for 2 weeks to ensure stable baseline behavior before repeating the acute cocaine challenge on task (for time line, see Fig. 1).

Immunohistochemistry. For the cell-counting experiment, all animals were perfused $24 \mathrm{~h}$ after their last drug exposure. $\Delta$ FosB immunoreactivity was detected using rabbit polyclonal antiserum (1:500; SC-48; Santa Cruz Biotechnology, Santa Cruz, CA). $\Delta$ FosB-positive cells were visualized using the avidin-biotin peroxidase method as described previously (Perrotti et al., 2004). All of the $\Delta$ FosB-like immunoreactivity seen represented $\Delta$ FosB and not full-length FosB, because no staining was found with an antibody selective for the full-length protein (data not shown) (Perrotti et al., 2004). The total number of $\Delta$ FosB-positive cells was counted in the prelimbic cortex (PrLC) and ventral OFC according to stereological methods using a Leeds microscope equipped with an $x-y-z$ stage connected to a personal computer running Bioquant Nova (Bioquant Image Analysis, Nashville, TN). Coded slides were used to count the number of $\Delta$ FosB-immunoreactive cells, and the code was not broken until the analysis was complete. Immunofluorescence was used to double or triple label for $\Delta$ FosB, calbindin, and calretinin (two markers of GABAergic interneurons in the rat frontal cortex), glial fibrillary acid protein (GFAP) (1:500; Z0334; DakoCytomation, Carpinteria, CA), or neuronal-specific nuclear protein $(\mathrm{NeuN})$, a neuronal marker (1:500; MAB377; Chemicon, Temecula, CA). The proteins were visualized using cyanine 2 (Cy2), Сy3, and Cy5 fluorophore-labeled secondary antibodies (1:200; Jackson Immunoresearch, West Grove, PA). Localization of protein expression was performed on a confocal microscope [Axiovert 100, Zeiss (Oberkochen, Germany) LSM 510 with META emission wavelengths 488, 543, and $633 \mathrm{~nm}$ ]. A confocal $Z$-stack was acquired and imported into Velocity (Improvision, Lexington, MA) for threedimensional rendering.

For analysis of viral expression, cells expressing GFP (1:500; ab6556; Abcam, Cambridge, MA), $\Delta$ FosB, or $\Delta$ JunD (1:1000; SC-74; Santa Cruz Biotechnology) were visualized using immunofluorescence. Two animals were excluded from the $\Delta$ FosB group attributable to lack of viral expression. As reported previously (Zachariou et al., 2006), the AAV vectors infected only neurons and did not cause detectable toxicity greater than that observed on control infusions.

Gene expression microarrays. Microarray analysis was performed as described previously (McClung and Nestler, 2003; McClung et al., 2005; Berton et al., 2006) with few modifications. Detailed methods following the MIAME format, which includes experimental design, sample and probe preparation, hybridization procedures and parameters, data analysis, and array design, can be found in supplemental data (available at www.jneurosci.org as supplemental material). Briefly, rats received bilateral intra-OFC injections of AAV-GFP, AAV- $\Delta$ FosB, or AAV- $\Delta$ JunD and were treated twice daily for $21 \mathrm{~d}$ with intraperitoneal saline or cocaine, exactly as described above. OFC tissue was dissected, and total RNA was extracted, converted to cDNA, amplified, and labeled according to the Affymetrix (Santa Clara, CA) protocols. This cRNA was hybridized to Affymetrix rat genome 2302.0 chip ( $\sim 30,000$ transcripts). We have a high degree of confidence in these array findings for several reasons. First, we used Affymetrix chips in which each gene is represented multiple times. Second, all animals were handled, treated, and killed at the same time, under the same conditions. As well, all RNA and array processing were run at the same time. Third, using our dissection criteria for the OFC, we performed pilot microarrays of this heterogeneous brain region to determine both the optimal number of animals to pool per array and the number of biological replicates per experimental condition. We performed triplicate arrays on independent tissue samples, with each sample representing tissue pooled from three animals. This protocol decreases differences attributable to individual variability and increases the statistical power of these experiments (Peng et al., 2003). Fourth, the data analysis criteria guidelines used for our study have been validated recently as having the highest degree of intersite reproducibility and interplatform and intraplatform reproducibility in the largest microarray study to date, which consists of $>1300$ microarrays from $>50$ institutions, including our own institution (Guo et al., 2006; MAQC Consortium, 2006). Indeed, in general, we find $<10 \%$ false positives in our microarray experiments (McClung and Nestler, 2003; Berton et al., 2006).

Data analysis. All data were analyzed using SPSS software (SPSS, Chicago, IL). Data for the cell-counting experiments from each area was initially analyzed by one-way ANOVA with drug condition as a betweensubjects factor. Student's $t$ tests were then conducted to compare saline with cocaine administration and to identify any effects of the different routes of administration. Data from the operant behavioral experiments were subjected to ANOVA with surgery as a between-subjects factor and session as a within-subjects factor. Data from the acute cocaine challenges were analyzed using multifactorial ANOVA with surgery as a between-subjects factor and dose of cocaine as a within-subjects factor. Subsequent ANOVA was performed to determine whether animals overexpressing either $\Delta \mathrm{FosB}$ or $\Delta \mathrm{JunD}$ were significantly different from GFP control animals. Delay was also included as a within-subjects factor for the delay-discounting experiments. Drug treatment group (i.e., chronic saline or cocaine) was included as a between-subjects factor to analyze the effects of acute cocaine after chronic cocaine treatment. Significant terms were clarified using simple main effects analysis and, when appropriate, Student's $t$ tests.

\section{Results}

\section{Increased induction of $\Delta$ FosB in the OFC after self- administration of cocaine}

Using immunohistochemistry, we compared $\Delta$ FosB expression in the PrLC, located in the medial prefrontal cortex, and the ventral OFC in animals that had self-administered cocaine for 3 weeks. Tissue from animals yoked to these self-administering rats, and from rats treated with twice-daily intraperitoneal injections of cocaine (two times with $15 \mathrm{mg} / \mathrm{kg}$ ) for the same amount of time, was also analyzed. As shown in Figure 2, increases in levels of $\Delta$ FosB were seen in both frontal areas after selfadministered, yoked, and intraperitoneal injections of cocaine when compared with saline controls (drug condition: PrLC, $F_{(4,25)}=8.547, p<0.0001$; OFC, $F_{(4,25)}=14.964, p<0.0001$; self-administered cocaine: $\operatorname{PrLC}, t_{(7)}=-4.222, p<0.002$; OFC, $t_{(7)}=-4.20, p<0.002$; yoked cocaine: $\operatorname{PrLC}, t_{(7)}=-2.75, p<$ 0.028 ; OFC, $t_{(7)}=-2.48, p<0.042$; intraperitoneal injections of cocaine: PrLC, $t_{(9)}=-3.96, p<0.003$; OFC, $t_{(9)}=-2.94, p<$ $0.016)$. However, induction of $\Delta$ FosB expression was dramatically more pronounced in the OFC after self-administered compared with forced administration of cocaine (yoked vs selfadministered cocaine: $t_{(8)}=-3.01, p<0.017$ ), whereas similar levels of induction were seen in the PrLC regardless of the course of drug administration $\left(t_{(8)}=-0.34, p<0.743\right.$, NS). In contrast to the OFC and PrLC, no induction of $\Delta$ FosB expression was observed in the primary motor cortex (M1), a region of the frontal cortex not implicated in drug addiction. $\Delta$ FosB-positive cells in both the PrLC and OFC are probably glutamatergic pyramidal neurons, because $\Delta$ FosB staining was colocalized with NeuN, a 
neuronal marker, but not with markers of GABAergic interneurons or GFAP, a glial marker (data not shown).

To control for the effects of operant learning per se, $\Delta$ FosB expression within the PrLC and OFC was determined in animals trained to press a lever to obtain a sucrose pellet for 3 weeks. Tissue from animals yoked to the self-administering animals, and also from those which received no sucrose reward in the chamber, was also processed. As shown in supplemental Figure S2 (available at www.jneurosci.org as supplemental material), no increases in $\Delta$ FosB levels were observed after this procedure in either frontal region under any of the behavioral conditions analyzed. Together, these data suggest that $\Delta$ FosBmediated changes in transcription specific to the OFC may be uniquely related to the development of cocaine addiction (Porrino et al., 2002).

\section{Overexpressing $\Delta$ FosB in the OFC} decreases changes in cognition induced by acute cocaine

After obtaining baseline measures of performance in the 5CSRT and delaydiscounting task, animals received intraOFC injections of an AAV vector expressing $\Delta$ FosB to mimic induction of the protein by cocaine or an AAV vector expressing $\Delta$ JunD to block the actions of endogenously induced $\Delta$ FosB. $\Delta$ JunD is a truncated, dominant-negative form of JunD, which binds to $\Delta$ FosB and inhibits its function (Peakman et al., 2003). Control animals received injections of an AAV vector expressing GFP. The localization and extent of viral-mediated overexpression is depicted in Figure 3. Pilot experiments demonstrated that maximal transgene expression was observed 8-10 d after surgery and that levels of this expression remained unchanged throughout a 6 month period. Animals expressing GFP, $\Delta \mathrm{FosB}$, or $\Delta \mathrm{JunD}$ in the OFC were then put through a series of experiments as depicted in Figure 1.

After reestablishing baseline performance of the animals after surgery in the 5CSRT and delay-discounting task, we studied the animals' performance in response to an acute dose of cocaine. Whereas overexpression of $\Delta$ FosB or $\Delta$ JunD did not alter baseline performance in either behavioral paradigm (supplemental Fig. S3, available at www.jneurosci. org as supplemental material), overexpression of $\Delta$ FosB blunted the response to acute cocaine. Within the 5CSRT paradigm, acute administration of cocaine to control animals (i.e., those expressing GFP) significantly reduced accuracy of target detection (Fig. $4 a$ : cocaine dose, $F_{(3,96)}=11.201$, frontal cortex.
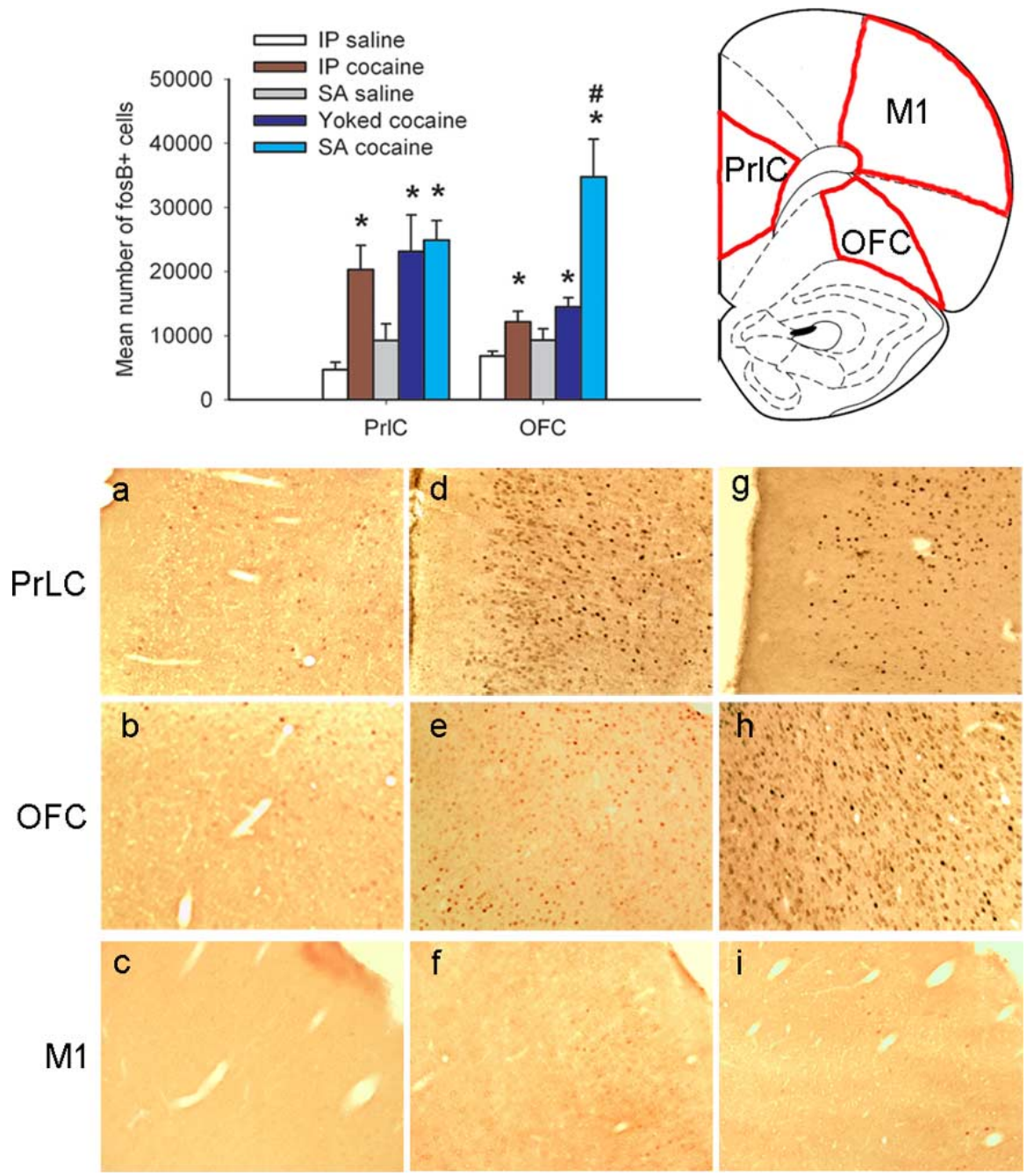

Figure 2. Chronic cocaine increases expression of $\Delta \mathrm{FosB}$ in frontal cortex. Panels indicate $\Delta \mathrm{FosB}$-positive cells in animals that were self-administering saline $(\boldsymbol{a}-\boldsymbol{c} ; n=5)$, yoked to animals self-administering cocaine $(\boldsymbol{d}-\boldsymbol{f} ; n=5)$, or self-administering cocaine $(\boldsymbol{g}-\boldsymbol{i} ; n=6)$. Compared with saline self-administering animals, increased numbers of $\Delta$ FosB-positive cells were observed in the PrLC and OFC after yoked and self-administered cocaine. Within the OFC only, a much greater increase was seen after self-administration compared with forced administration of cocaine. Chronic intraperitoneal (IP) cocaine injections $(n=6)$ caused similar levels of $\Delta \mathrm{Fos} B$ induction in both brain regions as seen with yoked cocaine infusions. No significant increases were seen in $M 1$, an area of frontal cortex not associated with addiction. Data shown are mean + SEM. * indicates significant difference from saline controls $(p<0.05)$; \# indicates a significant difference from yoked cocaine administration $(p<0.05)$.
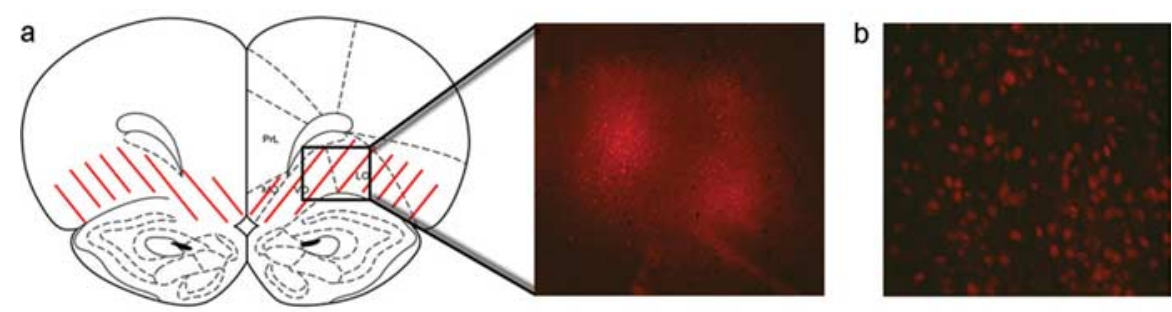

Figure 3. Viral-mediated gene transfer within the OFC. $\boldsymbol{a}, \mathrm{A}$ schematic of the area infected by the virus. Red diagonal lines indicate regions in which infected cells were observed. An example of AAV-mediated overexpression of $\Delta$ FosB within the area outlined by the black rectangle is shown in the middle, magnified $4 \times . \boldsymbol{b}$, Infected cells overexpressing $\Delta$ FosB at a higher magnification (20X). PrL, Prelimbic cortex; M0, medial orbitofrontal cortex; V0, ventral orbitofrontal cortex; LO, lateral orbito- 

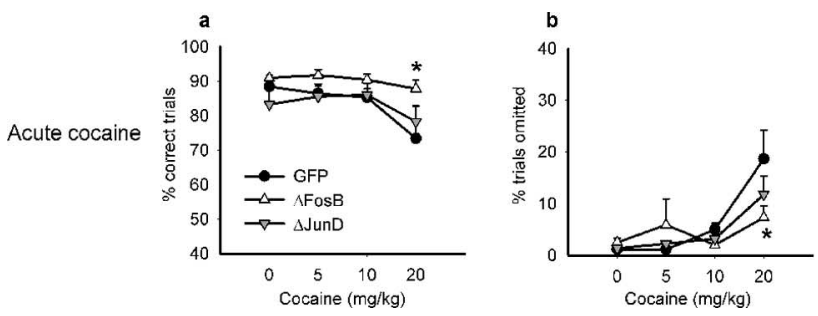

Figure 4. Effects of acute cocaine challenge on 5CSRT performance. Acute cocaine decreased performance accuracy $(\boldsymbol{a})$, an effect that was attenuated in animals overexpressing $\Delta$ FosB. Cocaine also increased omissions $(\boldsymbol{b})$, yet animals overexpressing $\Delta$ FosB omitted fewer trials at higher doses. Cocaine increased premature responding in all animals (c). Data shown are mean + SEM. ${ }^{*} p<0.05$.
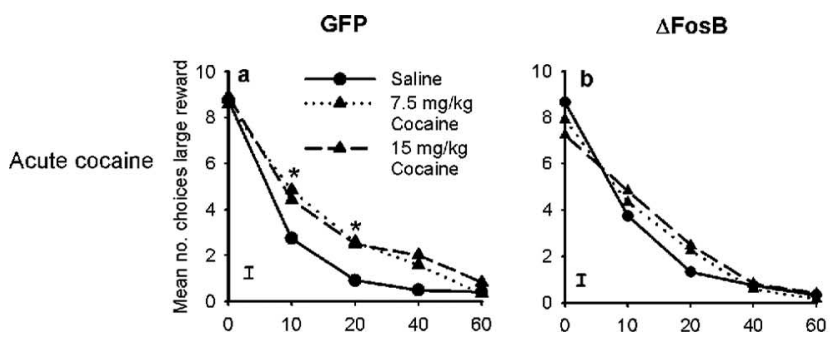

Figure 5. Effects of acute cocaine challenge on delay-discounting performance. Acute cocaine increased choice of the large delayed reward in control animals $(\boldsymbol{a})$. This effect was diminished in animals overexpressing $\Delta \mathrm{FosB}(\boldsymbol{b})$ but still evident in those overexpressing $\Delta \operatorname{JunD}(\boldsymbol{c})$. The inset to c summarizes these data and shows the number of times animals chose the large reward when given cocaine $(15 \mathrm{mg} / \mathrm{kg})$ minus their choice of the large reward when given saline. ${ }^{*} p<0.05$.

rial): cocaine dose, $\left.F_{(3,96)}=10.409, p<0.001\right]$, indicative of both an attentional and motivational impairment. Overexpression of $\Delta$ FosB in this region consistently attenuated the ability of cocaine to impair task performance. When given cocaine, animals overexpressing $\Delta$ FosB were more accurate compared with controls (GFP vs $\Delta$ FosB, group: $\left.F_{(1,21)}=10.448, p<0.004\right)$ and also omitted fewer trials than control rats, an effect that was significant at higher doses of cocaine (GFP vs $\Delta$ FosB, dose $\times$ group: $F_{(3,63)}=4.245, p<0.013$; saline vs cocaine at $10 \mathrm{mg} / \mathrm{kg}$, dose $\times$ group: $F_{(1,21)}=16.991, p<0.0001$; saline vs cocaine at $20 \mathrm{mg} / \mathrm{kg}$, dose $\times$ group: $\left.F_{(1,21)}=6.880, p<0.016\right)$. Similarly, overexpression of $\Delta$ FosB prevented higher doses of cocaine from decreasing the number of trials completed at the highest dose (GFP vs $\Delta$ FosB, dose $\times$ group: $F_{(3,63)}=4.855, p<0.004$; saline vs cocaine at $20 \mathrm{mg} / \mathrm{kg}$, dose $\times$ group: $\left.F_{(1,21)}=4.660, p<0.043\right)$.

In contrast to $\Delta \mathrm{FosB}$, overexpression of $\Delta \mathrm{JunD}$ did not alter these effects of acute cocaine on task performance (GFP vs $\Delta$ JunD, accuracy, group: $F_{(1,23)}=0.112$, NS; dose $\times$ group: $F_{(3,69)}$ $=1.731$, NS; omissions, group: $F_{(1,23)}=0.914$, NS; dose $\times$ group: $F_{(3,69)}=1.781$, NS; trials completed, group: $F_{(1,23)}=0.130$, NS; dose $\times$ group: $F_{(3,69)}=0.122$, NS). Cocaine also increased premature responding in all animals regardless of surgery group (Fig. $4 c$ : cocaine dose, $F_{(3,96)}=24.699, p<0.001$; GFP vs $\Delta$ FosB, group: $F_{(1,21)}=1.480$; dose $\times$ group: $F_{(3,63)}=1.308$, NS; GFP vs $\Delta$ JunD: $F_{(1,23)}=0.076$, NS; dose $\times$ group: $\left.F_{(3,69)}=1.119, \mathrm{NS}\right)$.

Overexpression of $\Delta$ FosB in the OFC produced a similar attenuation of the ability of cocaine to alter an animal's functioning in the delay-discounting task (Fig. 5). In this paradigm, acute cocaine exposure increased choice of the larger delayed reward. This may seem paradoxical given reports that cocaine increases impulsive decision making; however, both D-amphetamine and OFC lesions promote choice of the larger delayed reward (Wade et al., 2000; Winstanley et al., 2004). One interpretation of these data are that individuals persist in choosing the larger reward, disregarding the adverse conse-
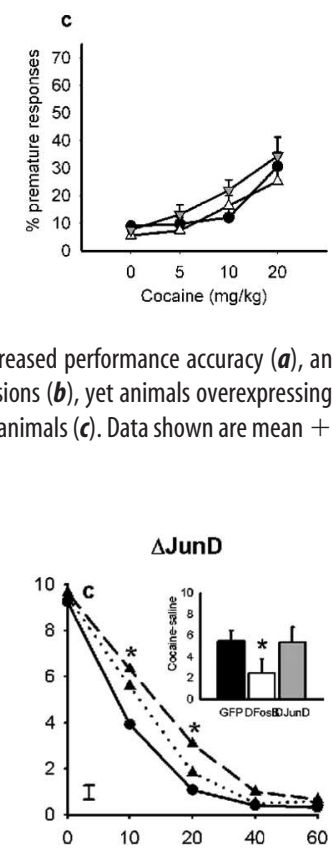

quence of delay, a concept termed "myopia for the future" (Bechara and Damasio, 2002). Cocaine addicts and OFC-damaged patients display this behavior when performing laboratorybased gambling tasks (Bechara et al. 1999; Bechara and Damasio, 2002). Increasing $\Delta$ FosB levels in the OFC tended to reduce the effects of acute cocaine in this paradigm (GFP vs $\Delta$ FosB, dose $\times$ group: $\left.F_{(2,68)}=2.555, p<0.065\right)$. Whereas control animals showed a robust increase in choice of the large reward after administration of cocaine, this effect was absent in animals overexpressing $\Delta$ FosB (Fig. 5a: GFP animals, dose: $F_{(2,46)}=12.105, p<0.001$; Fig. $5 b$ : $\Delta$ FosB animals, dose: $F_{(2,22)}=0.479$, NS). The number of choices of the larger delayed reward appeared to be slightly higher in animals overexpressing both $\Delta$ FosB and $\Delta$ JunD when given saline, but these differences were not statistically significant (GFP vs $\Delta$ FosB, group $F_{(1,34)}=0.088$, NS; GFP vs $\Delta$ JunD, group: $F_{(1,34)}=0.260$, NS). When the data were transformed to take into account this baseline variation [(total number of choices of the large reward after cocaine) - (total number of choices of the large reward after saline)], animals expressing $\Delta$ FosB made significantly fewer choices of the large reward when given cocaine, confirming our interpretation of the data that $\Delta$ FosB reduces this effect of acute cocaine (Fig. $5 c$, inset: cocaine $15 \mathrm{mg} / \mathrm{kg}$ : GFP vs $\Delta \mathrm{FosB}, t_{(34)}=1.983, p<$ $0.05)$. In contrast, overexpression of $\Delta \mathrm{JunD}$ did not alter the response to cocaine in either analysis (Fig. $5 c$ : GFP vs $\Delta$ JunD cocaine dose $\times$ group: $F_{(2,68)}=0.241$, NS; Fig. $5 c$, inset: cocaine at $15 \mathrm{mg} / \mathrm{kg}$ : GFP vs $\Delta$ JunD, $t_{(34)}=1.157$, NS).

\section{Chronic cocaine administration produces tolerance to some of the effects of acute cocaine on cognition, which is mimicked by $\Delta$ FosB and blocked by $\Delta$ JunD}

After 1 week of rebaselining, animals received chronic intraperitoneal injections of cocaine or saline for 3 weeks (Fig. 1). This chronic exposure to cocaine did not alter performance in the 5CSRT or delay-discounting task in control (GFP expressing) animals or in those overexpressing $\Delta$ FosB. However, during the third week of cocaine treatment, animals overexpressing $\Delta \mathrm{JunD}$ in the OFC increased their choice of the larger delayed reward, mimicking the effects of acute cocaine, indicative of increased sensitivity to chronic drug treatment (day $\times$ delay $\times$ group $\times$ chronic treatment: $F_{(56,1120)}=1.351, p<0.046$; week 3; cocainetreated animals, delay $\times$ group: $F_{(4,40)}=3.024, p<0.029$; data not shown). This behavioral change was transient: after 2 weeks of drug-free testing, the performance of all groups was identical to that of saline-treated controls (delay $\times$ group $\times$ chronic treatment: $\left.F_{(4,80)}=0.817, \mathrm{NS}\right)$.

We next challenged these animals with an acute dose of cocaine (Fig. 1) and found that chronic administration of cocaine produced tolerance, not sensitization, to some aspects of the cognitive disruption caused by acute cocaine. Thus, the effects of previous chronic cocaine exposure paralleled those of $\Delta$ FosB in the previous experiment (Figs. 4, 5). A summary of these data, 
Table 1. Summary of the effects of an acute cocaine challenge on cognitive function after chronic treatment with cocaine or saline.

\begin{tabular}{|c|c|c|c|c|}
\hline Variable & Group & Main interactions & Follow-up analyses & $\begin{array}{l}\text { Effects of acute cocaine challenge after chronic } \\
\text { cocaine or saline treatment }\end{array}$ \\
\hline Accuracy & $\begin{array}{l}\text { GFP versus } \Delta \text { FosB } \\
\text { GFP versus } \Delta \text { JunD }\end{array}$ & $\begin{array}{l}\text { Dose } \times \text { group, } F_{(3,57)}=3.763, p<0.016 \\
\text { Dose } \times \text { group } \times \text { chronic treatment, } \\
F_{(3,57)}=0.706, \text { NS } \\
\text { Dose } \times \text { group, } F_{(3,60)}=1.576, \mathrm{NS} \\
\text { Dose } \times \text { group } \times \text { chronic treatment, } \\
F_{(3,60)}=2.074, \mathrm{NS}\end{array}$ & & $\begin{array}{l}\text { Animals overexpressing } \Delta \text { FosB were more } \\
\text { accurate, after the acute cocaine challenge, } \\
\text { regardless of chronic treatment with cocaine or } \\
\text { saline, whereas overexpression of } \Delta \text { JunD did } \\
\text { not affect accuracy. }\end{array}$ \\
\hline Omissions & GFP versus $\Delta$ JunD & $\begin{array}{l}\text { Dose } \times \text { group } \times \text { chronic treatment, } \\
F_{(3,57)}=2.949, p<0.04\end{array}$ & $\begin{array}{l}\text { GFP, dose } \times \text { chronic treatment, } \\
F_{(3,30)}=14.008, p<0.001 \\
\Delta \text { FosB, dose } \times \text { chronic treatment, } \\
F_{(3,27)}=0.286, \text { NS } \\
\Delta \text { JunD, dose } \times \text { chronic treatment, } \\
F_{(3,30)}=2.321, \text { NS }\end{array}$ & $\begin{array}{l}\text { GFP control animals treated chronically with } \\
\text { cocaine made fewer omissions in response to } \\
\text { the acute cocaine challenge compared with } \\
\text { animals treated chronically with saline. This } \\
\text { effect was mimicked in rats overexpressing } \\
\Delta \text { FosB (omissions were uniformly low regard- } \\
\text { less of chronic treatment) and blocked in ani- } \\
\text { mals overexpressing } \Delta \text { JunD (omissions were } \\
\text { uniformly high regardless of chronic treatment). }\end{array}$ \\
\hline Premature responses & $\begin{array}{l}\text { GFP versus } \Delta \text { FosB } \\
\text { GFP versus } \Delta \text { JunD }\end{array}$ & $\begin{array}{l}\text { Dose } \times \text { group } \times \text { chronic treatment, } \\
F_{(3,57)}=1.991, p<0.075 \\
\text { Dose } \times \text { group } \times \text { chronic treatment, } \\
F_{(3,60)}=2.101, p<0.069\end{array}$ & $\begin{array}{l}\text { Cocaine-treated rats, } 20 \mathrm{mg} / \mathrm{kg}, t_{(12)} \\
=2.435, p<0.031 \\
\text { Cocaine-treated rats, } 20 \mathrm{mg} / \mathrm{kg}, t_{(12)} \\
=-2.025, p<0.048\end{array}$ & $\begin{array}{l}\text { In the chronic cocaine-treated group, animals } \\
\text { overexpressing } \Delta \text { FosB tended to make fewer } \\
\text { premature responses when given an acute } \\
\text { challenge with the highest dose of cocaine, } \\
\text { whereas animals overexpressing } \Delta \text { JunD tended } \\
\text { to make more premature responses. }\end{array}$ \\
\hline Impulsive choice & GFP versus $\Delta$ JunD & $\begin{array}{l}\text { Dose } \times \text { delay } \times \text { group, } F_{(8,256)}=1.883 \text {, } \\
p<0.056 \\
\text { Dose } \times \text { group } \times \text { delay } \times \text { chronic treat- } \\
\text { ment, } F_{(8,256)}=1.331, p<0.085 \\
\text { Dose } \times \text { delay } \times \text { group, } F_{(8,256)}=1.981 \text {, } \\
p<0.049 \\
\text { Dose } \times \text { delay } \times \text { group } \times \text { chronic treat- } \\
\text { ment, } F_{(8,256)}=1.881, p<0.055\end{array}$ & $\begin{array}{l}\text { GFP dose } \times \text { chronic treatment, } \\
F_{(3,264)}=3.484, p<0.021 \\
\Delta \text { FosB dose } \times \text { chronic treatment, } \\
F_{(3,120)}=0.158, \text { NS } \\
\Delta \text { JunD dose } \times \text { chronic treatment, } \\
F_{(3,120)}=1.233, \text { NS }\end{array}$ & $\begin{array}{l}\text { GFP control animals no longer show a response } \\
\text { to the acute cocaine challenge after previous } \\
\text { chronic cocaine treatment. This effect was mim- } \\
\text { icked in rats overexpressing } \Delta \text { Fos } B \text { (no effect of } \\
\text { drug regardless of chronic treatment) and } \\
\text { blocked in animals overexpressing } \Delta \text { JunD (ef- } \\
\text { fect of drug regardless of chronic treatment). }\end{array}$ \\
\hline
\end{tabular}

plus the main significant interactions from the ANOVAs, are provided in Table 1. The chronic cocaine injections were given to rats in their home cages; therefore, the tolerance-like effects appear to be independent of the context in which the animals received drug.

On the 5CSRT, in parallel to our initial observations, control animals that had been chronically treated with saline showed a robust increase in omissions when given an acute cocaine challenge, in contrast to saline-treated animals overexpressing $\Delta$ FosB that showed a significantly muted response to the drug (Fig. 6b) (saline animals only, dose $\times$ group: $F_{(3,24)}$ $=7.755, p<0.001$ ). However, control (GFP expressing) rats previously treated chronically with cocaine did not omit as many trials when given an acute cocaine challenge (Fig. 6e). The performance of these animals was now indistinguishable from those overexpressing $\Delta \mathrm{FosB}$, in that both were showing a "tolerance-like" effect (GFP vs $\Delta$ FosB, cocaine animals only, dose $\times$ group, $\left.F_{(3,33)}=0.167, \mathrm{NS}\right)$. In contrast, animals overexpressing $\Delta$ JunD continued to omit many trials when given cocaine, regardless of whether they had received previous chronic treatment with cocaine or saline. It would therefore appear that overexpressing $\Delta \mathrm{JunD}$ within the OFC prevented the development of tolerance to the amotivational effects of cocaine on this task.

Acute cocaine still produced impairments in performance accuracy in animals treated chronically with saline or with cocaine, impairments that were again reduced in animals overexpressing $\Delta$ FosB (Fig. $6 a, d$ ). Likewise, animals treated chronically with cocaine were still more impulsive after an acute cocaine challenge (Fig. 6c,f). However, after chronic cocaine treatment, animals overexpressing $\Delta$ JunD made more premature responses at the highest dose of the drug, whereas animals overexpressing $\Delta$ FosB made less. Once again, overexpression of $\Delta$ JunD appears to exacerbate the effects of an acute cocaine challenge, whereas overexpression of $\Delta$ FosB appears to counter the effects of the drug.

A similar pattern of effects was observed in the delaydiscounting task. Chronic intraperitoneal administration of cocaine in the animals' home cage induced tolerance to the effects of an acute cocaine challenge in control (GFP expressing) animals. Whereas animals treated chronically with saline still showed a robust increase in choice of the larger delayed reward in response to the cocaine challenge (Fig. $7 a$ : dose $\times$ delay: $F_{(2,88)}=3.647$, $p<0.001)$, this effect was absent in animals treated chronically with cocaine (Fig. $7 d$ : dose $\times$ delay, $F_{(2,88)}=0.687$, NS). As observed previously, saline-treated animals overexpressing $\Delta$ FosB did not alter their choice behavior in response to acute cocaine (Fig. $7 b$ : $\Delta$ FosB chronic saline group: dose $\times$ delay, $F_{(8,40)}$ $=0.554$, NS; Fig. $7 d$ : chronic cocaine group, $F_{(8,40)}=1.867$, NS). In this regard, overexpression of $\Delta \mathrm{FosB}$ in the OFC mimics the effects of chronic cocaine administration. Furthermore, overexpression of $\Delta$ JunD again prevented the ability of chronic cocaine treatment to blunt the effects of an acute cocaine challenge. Animals in this group still showed a significant change in choice behavior when given acute cocaine, regardless of whether they had received previous chronic treatment with saline or cocaine 

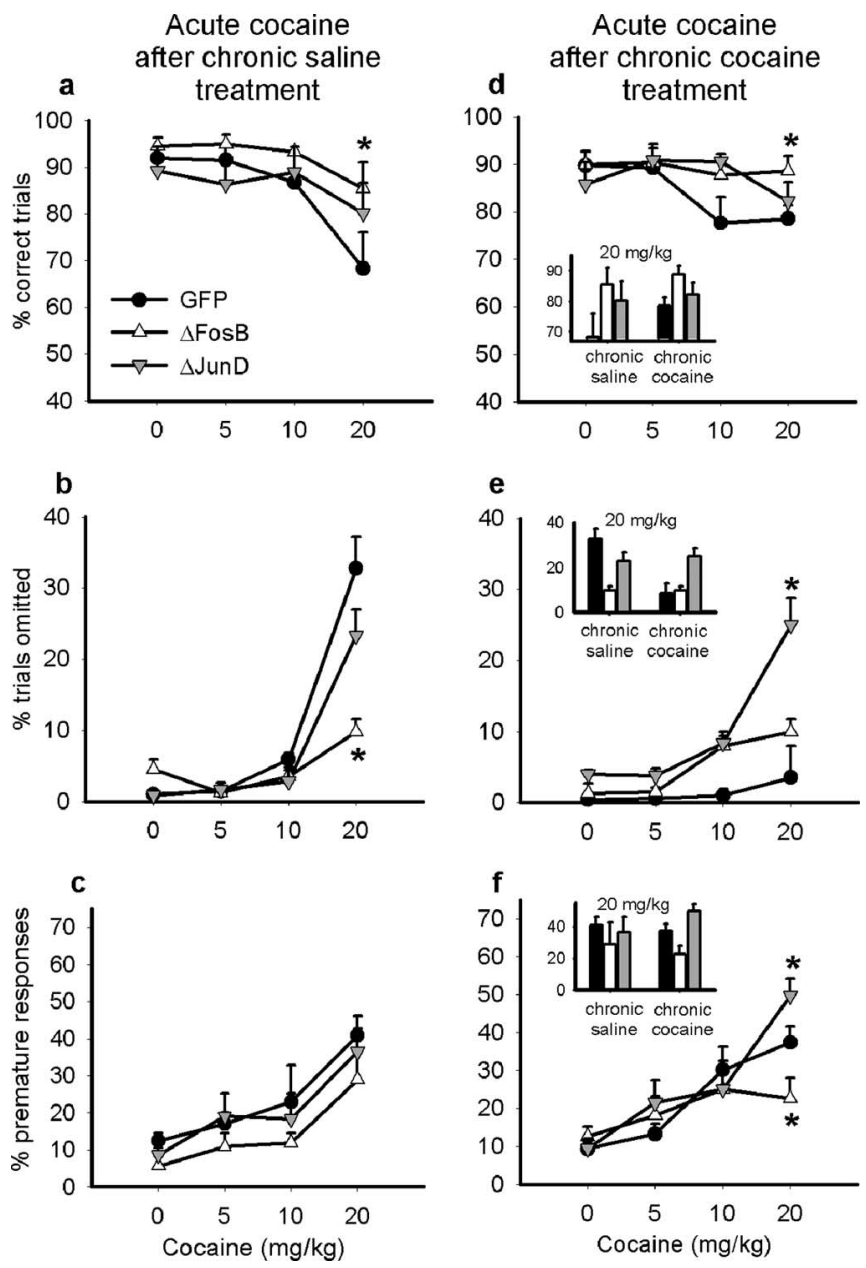

Figure 6. Effects of an acute cocaine challenge on 5CSRT performance after previous chronic treatment with saline or cocaine. The effects of an acute cocaine challenge on task performance were not altered by previous chronic treatment with saline. Animals were less accurate $(\boldsymbol{a})$ and made more omissions $(\boldsymbol{b})$, effects that were attenuated in animals overexpressing $\Delta$ FosB. All animals continued to make more premature responses (c). After chronic cocaine treatment, an acute cocaine challenge impaired accuracy in all animals other than those overexpressing $\Delta$ FosB (d). However, control (GFP expressing) animals treated chronically with cocaine made fewer omissions when subsequently challenged with cocaine on task (e). This effect was mimicked by overexpressing $\Delta$ FosB and blocked by overexpressing $\Delta$ JunD (e.g., at $20 \mathrm{mg} / \mathrm{kg}$, inset graph). After chronic cocaine treatment, the acute cocaine-induced increase in premature responding was reduced in animals overexpressing $\Delta$ FosB but augmented in animals overexpressing $\Delta$ JunD ( $\boldsymbol{f}$; e.g., at $20 \mathrm{mg} / \mathrm{kg}$, inset graph). Data shown are mean + SEM. ${ }^{*} p<0.05$.

(Fig. 7c: $\Delta$ JunD chronic saline group, dose $\times$ delay, $F_{(8,40)}=$ 2.816, $p<0.014$; Fig. $7 f: \Delta$ JunD chronic cocaine group, dose, $\left.F_{(2,20)}=4.303, p<0.045\right)$. These findings further demonstrate that overexpression of $\Delta \mathrm{JunD}$ in the OFC blocked the development of tolerance to the drug.

\section{Cocaine regulation of gene expression in the OFC: effects of $\Delta$ FosB and $\Delta$ JunD}

To better understand the mechanisms by which chronic cocaine administration alters OFC function and to gain insight into how $\Delta$ FosB mediates aspects of cocaine action, we performed microarray experiments to examine gene expression profiles of this brain region. The control group for this experiment were salinetreated rats that were infected with AAV-GFP ("saline-GFP"). These control animals were compared against: (1) the effects of chronic cocaine ("cocaine-GFP"), (2) the effects of $\Delta$ FosB in the absence of cocaine ("saline- $\Delta$ FosB"), and (3) the effects of
$\Delta$ JunD along with chronic cocaine ("cocaine- $\Delta$ JunD"). Chronic administration of cocaine was found to significantly regulate 276 genes in the OFC; 162 genes were upregulated and 114 genes were downregulated (Fig. 8a). A list of these cocaine-regulated genes is provided in Table S2a (supplemental data, available at www.jneurosci.org as supplemental material). Strikingly, overexpression of $\Delta$ JunD blocked the ability of chronic cocaine to regulate the large majority $(\sim 80 \%)$ of these genes (Fig. $6 a$ ) (Table S2a, available at www.jneurosci.org as supplemental material). Conversely, overexpression of $\Delta$ FosB by itself, in the absence of cocaine exposure, mimicked the effect of chronic cocaine on $\sim 10 \%$ of these genes, with trends toward similar regulation seen for many additional genes, as depicted in the heat maps shown in Figure $8 a$. Moreover, $\Delta$ FosB overexpression significantly upregulated or downregulated 68 genes in the OFC, and $\sim 40 \%$ of these showed similar regulation by chronic cocaine (Fig. $8 b$ ) (Table $\mathrm{S} 2 b$, available at www.jneurosci.org as supplemental material). Together, these findings document that induction of $\Delta$ FosB in the OFC mediates a significant portion of the effects of chronic cocaine on gene expression within this brain region. These findings are all the more striking because of the technical constraints on this experiment, namely, that our viral injections, although they infect a significant fraction of the OFC, do not infect the entire region (Fig. 3). This makes it all the more impressive that $A A V-\Delta$ FosB and AAV $-\Delta J u n D$, respectively, were able to mimic and block some of the effects of cocaine on gene expression in the $\mathrm{OFC}$ and suggests that the true effects of these proteins are likely underrepresented by our findings.

Molecular pathway analysis of the genes that showed interesting patterns of regulation by cocaine and by $\Delta$ FosB revealed concerted biochemical pathways that could account for the behavioral effects observed in this study. We found that chronic cocaine has dramatic effects on genes that mediate glutamatergic transmission and its intracellular consequences, including genes for AMPA, NMDA, and metabotropic glutamate (mGluR) receptors, intracellular $\mathrm{Ca}^{2+}$ signaling proteins, and proteins that regulate gene expression [e.g., CREB binding protein (CBP) or cAMP response element-binding protein (CREB) binding protein] (supplemental Fig. S4, available at www.jneurosci.org as supplemental material). The ability of chronic cocaine to potentiate glutamatergic transmission in frontal cortical regions is well documented (Kalivas and Volkow, 2005), and our findings provide some of the possible molecular underpinnings for this effect. Induction of CBP is interesting in light of its role in serving as a critical transcriptional coactivator with CREB, AP-1, and other transcription factors. Other prominently regulated genes, in related functional pathways, are those for $\mathrm{GABA}_{\mathrm{A}}$ receptor subunits, substance $\mathrm{P}$, and guanylyl cyclase. Although $\Delta \mathrm{FosB}$ overexpression did not mimic all of these effects of cocaine, it did mimic the effects of cocaine on mGluRs, $\mathrm{GABA}_{\mathrm{A}}$ receptor subunits, substance $\mathrm{P}$, guanylyl cyclase, and protocadherin 7. Several of these genes have been shown to regulate cortical function and could account for the behavioral findings of this study (see Discussion).

\section{Discussion}

The results of this study demonstrate that the ability of chronic cocaine to induce expression of $\Delta$ FosB in the OFC is much more pronounced if animals self-administer the drug. Our data demonstrate further that chronic intraperitoneal cocaine treatment causes tolerance to some of the deleterious effects of cocaine on cognitive performance, in terms of both motivation and decision making. Increasing $\Delta$ FosB levels in the OFC, achieved by viral- 
mediated gene transfer, mimics this tolerance, whereas $\Delta$ JunD (a dominantnegative antagonist of $\Delta$ FosB) blocks it. Together, these results indicate that druginduced expression of $\Delta$ FosB in the OFC is one likely mechanism underlying this behavioral tolerance.

The finding that $\Delta$ FosB is differentially regulated by volitional versus forced $\mathrm{co}^{-}$ caine administration in the OFC, but not in PrLC, highlights distinct responses to cocaine within frontal regions. Given the pronounced role for the PrLC in detecting instrumental contingencies, one might have expected greater $\Delta$ FosB induction in this region, rather than the OFC, after cocaine self-administration (Balleine and Dickinson, 1998). However, detection of a causal relationship between actions and outcomes does not appear to be driving $\Delta$ FosB expression, a finding underscored by the lack of $\Delta$ FosB induction after sucrose self-administration. The fact that there is no difference in $\Delta$ FosB induction in PrLC after self- versus experimenteradministered cocaine suggests further that $\Delta$ FosB expression in this region does not reflect contingency learning but rather some pharmacological action of the drug. Although we do not address the functional consequences of $\Delta$ FosB expression in the PrLC, we conclude that it likely contributes to a behavioral change observed after both self- and experimenter-administered cocaine, the exact nature of which remains to be determined.

Given that instrumental contingency does not appear to be the driving force for inducing $\Delta \mathrm{FosB}$ in frontal cortex, the question remains why $\Delta \mathrm{FosB}$ expression in the $\mathrm{OFC}$ is so much greater after self-administered cocaine. Although both the PrLC and OFC are involved in aspects of executive function and goaldirected behavior, the OFC in particular has a pronounced role in encoding the sensory-specific values of affective stimuli and in updating representations of rewards when their value changes (Schoenbaum et al., 1999; Rolls, 2006). Theoretically, altered gene expression within the OFC during cocaine selfadministration could reflect changes in the hedonic or incentive value of the drug that are more pronounced after self- versus experimenter-administered drug, although the large literature on conditioned place preference suggests that rats find cocaine injections pleasurable (Bardo et al., 1995). However, during the course of self-administration, animals learn to regulate their intake on the basis of the rewarding or aversive sensation of increasing drug use. Although damage to either the PrLC or OFC facilitates acquisition of cocaine self-administration, OFC lesions also prevent animals from developing the characteristically stable patterns of responding observed during cocaine self-administration sessions (Weissenborn et al., 1997; Hutcheson and Everitt, 2003). This indicates that OFC dysfunction impairs regulation of cocaine intake, potentially attributable to an inability to update representations of reward value, which could increase the likelihood of escalating drug use and dependency. Whether these impairments involve an increase in $\Delta$ FosB expression remains unknown. Understanding the different contributions made by distinct frontal regions to aspects of addiction clearly merits additional investigation.
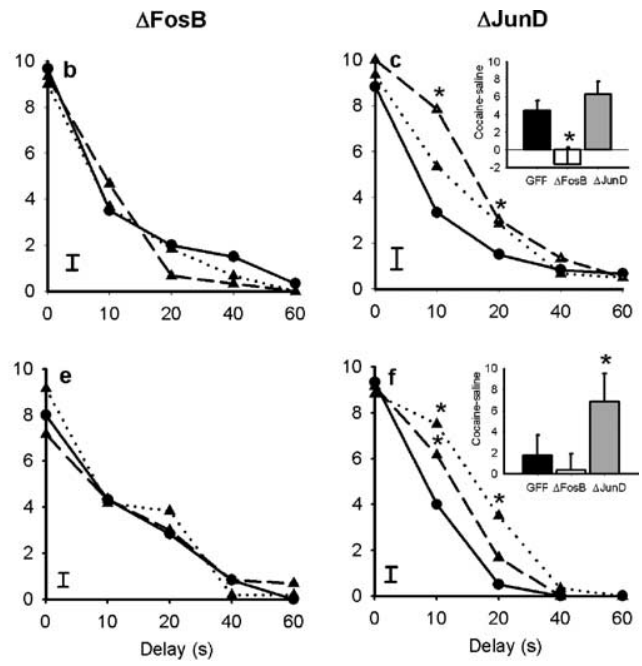

GFP

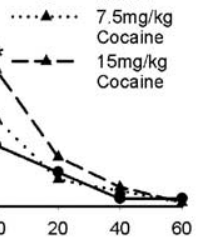

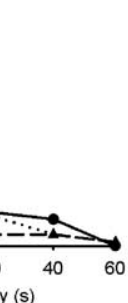

Effects of an acute cocaine challenge on delay-discounting performance after previous chronic treatment with salin (a) a cote cocine challenge no longer altered impulsive decision making in control animals (d) or in animals overexpressing $\Delta$ FosB $(\boldsymbol{e})$. Animals overexpressing $\Delta$ JunD did not develop any tolerance to the effects of cocaine $(\boldsymbol{f})$. Data shown are mean +

Tolerance to some of the cognitive effects of acute cocaine observed after chronic drug treatment replicates and extends the finding that animals with a history of self-administering cocaine show reduced premature responding when given an amphetamine challenge (Dalley et al., 2005a). Collectively, these data suggest that the brain adapts to the repeated effects of cocaine, leading to a reduction in cognitive disturbances induced by acute drug exposure. Although this adaptation may allow the OFC to function better when drug is onboard, it may also contribute to the cognitive impairments observed after cessation of drug use, potentially through reducing the sensitivity of the OFC to normal stimuli. A role for $\Delta$ FosB in compensating for excessive cortical activation has been suggested previously (Powell et al., 2006) and may explain why $\Delta$ FosB expression in OFC reduces the disruptive effects of cocaine. Although animals in the current study did not alter their behavioral performance when intraperitoneal cocaine dosing was stopped, probably because they were well trained in the tasks and no new learning was required, a similar dosing regimen has been shown to impair acquisition of reversal learning during withdrawal (Schoenbaum et al., 2004). Addicts may therefore take cocaine in part as a form of self-medication, that is, to remedy the cognitive dysfunction evident in withdrawal. Alternatively, relapse to drug-seeking could arise through impairments in OFC function caused by chronic drug exposure that become more evident once drug-taking ceases. Additional work is needed to study these and additional possibilities.

OFC damage causes a similar pattern of effects as psychostimulant administration, increasing premature responding and omissions on the 5CSRT while decreasing impulsive choice in delay-discounting, suggesting that both overstimulation and understimulation of this region impairs cognitive function (Cole and Robbins, 1987; Chudasama et al., 2003; Winstanley et al., 2003 , 2004). Evidence suggests that activity of the OFC is reduced in abstinent cocaine addicts, although aberrant overactivity in this region has also been reported in addicts when engaged in laboratory-based gambling tasks (Ersche et al., 2005, 2006). The 
a
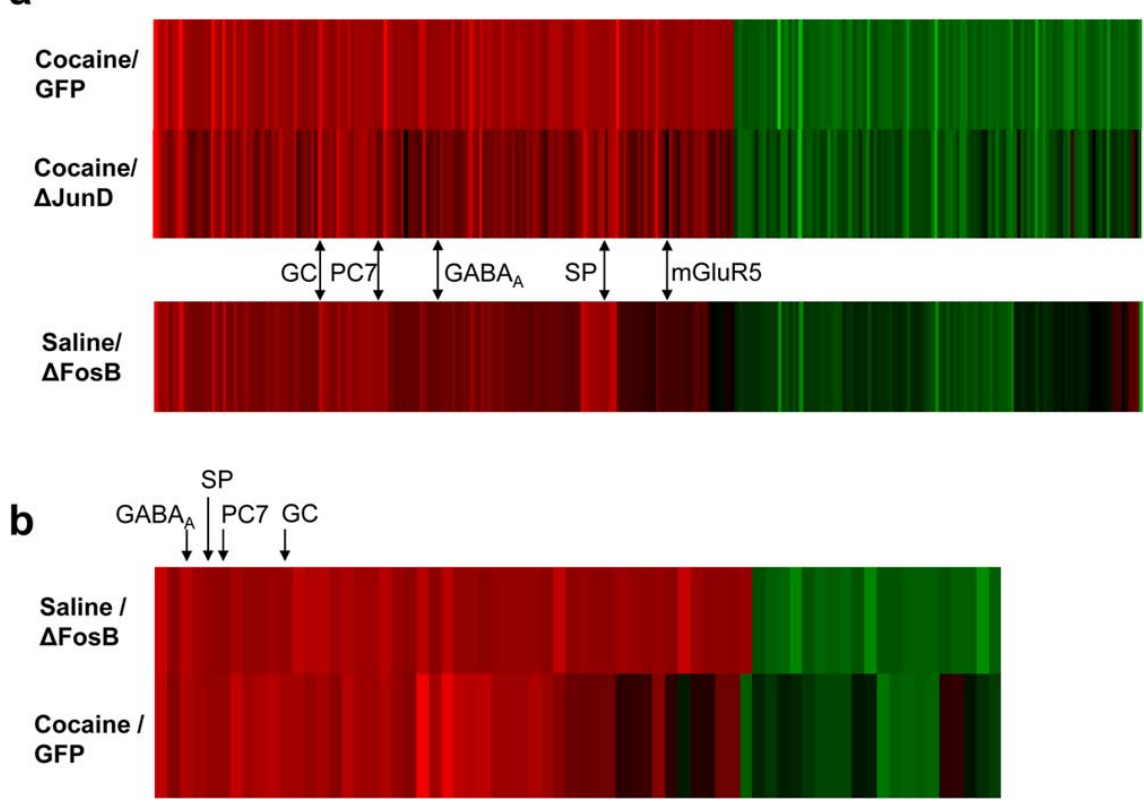

Figure 8. Regulation of gene expression in OFC by cocaine: effects of $\Delta F$ osB and $\Delta$ JunD. Gene expression in the OFC was evaluated using gene profiling. $\boldsymbol{a}$, Hierarchical clusters of genes significantly upregulated or downregulated in the OFC of AAVGFP-injected rats by chronic intraperitoneal cocaine administration and how they are regulated by other experimental conditions. The results show that $\Delta \mathrm{JunD}$ attenuates cocaine regulation of most of these genes, whereas $\Delta \mathrm{Fos} B$ by itself, in the absence of cocaine, tends to produce effects similar to cocaine. $\boldsymbol{b}$, Hierarchical clusters of genes significantly regulated in the OFC of AAV$\Delta$ FosB-injected rats and how they are regulated by chronic cocaine. The results show that most $\Delta$ FosB-regulated genes show similar regulation by cocaine. The intensity and direction of gene regulation are represented with a heat map (red, upregulated; green, downregulated). GC, Guanylyl cyclase, $\alpha_{3}$ subunit; $\mathrm{PC7}$, protocadherin $7 ; \mathrm{GABA}_{\mathrm{A}^{\prime}} \alpha_{6}$ and $\beta_{1}$ subunits; SP, substance P. For detailed experimental protocol, complete gene lists, and molecular pathway analysis of regulated genes, see supplemental data (available at www.jneurosci.org as supplemental material).

underactivity at baseline may therefore belie an increased sensitivity to stimulation under some conditions. Addicts who exhibit reduced basal levels of OFC activity also show an aberrant increase in blood flow to this region after administration of the cocaine analog procaine, an effect not observed in control subjects (Adinoff et al., 2001). Nevertheless, the mechanisms underlying the decrease in cortical activity observed under baseline conditions remains unclear.

One possibility is that local inhibitory circuits may be engaged to compensate for the increased excitatory response caused by repeated psychostimulant administration (Kalivas and Volkow, 2005). Such compensatory processes could underlie dampened cortical responses to external stimulation, which would then mediate behavioral tolerance to the effects of cocaine on cognition. Our gene expression microarray findings provide novel insight into this critical question: $\mathrm{GABA}_{\mathrm{A}}$ receptor subunits, substance $\mathrm{P}$, and the mGluR5, each of which has been shown to dampen cortical activity, are upregulated within the OFC by chronic cocaine and during overexpression of $\triangle \mathrm{FosB}$, and cocaine regulation of these genes is blocked by overexpression of $\Delta$ JunD.

$\mathrm{GABA}_{\mathrm{A}}$ receptors are located on both local interneurons and glutamatergic pyramidal cells within frontal cortex and mediate rapid hyperpolarization (Dunn et al., 1996). Repeated administration of cocaine has been shown to decrease GABAergic transmission through $\mathrm{GABA}_{\mathrm{A}}$ receptors (Huang et al., 2007), indicating that the induction of these receptors observed in the current study could represent the attempt by the brain to compensate for cocaine-induced overactivation of cortical circuitry. Cocaine applied in vitro to septal slice preparations taken from animals treated chronically with cocaine reveals an increased number of cells showing hyperpolarizing rather than depolarizing responses (Shoji et al., 1998), suggesting that the compensatory upregulation of $\mathrm{GABA}_{\mathrm{A}}$ receptors shown here could lead to a reduction in excitatory responses to cocaine. Substance $\mathrm{P}$ is present in a subpopulation of cortical GABAergic interneurons (Penny et al., 1986) and acts at excitatory G-protein-coupled neurokinin-1 receptors $\left(\mathrm{NK}_{1}\right)$ within frontal cortex (Saffroy et al., 2003). Substance P-induced excitation of GABAergic interneurons after increased activation of cortical pyramidal neurons has been implicated in models of epilepsy, because substance $P$ promotes the release of GABA within the entorhinal cortex and can attenuate epileptiform activity in this region (Maubach et al., 1998; Stacey et al., 2002). Likewise, activation of mGluR5 in cortex has been shown to increase GABAmediated inhibition through excitation of inhibitory interneurons (Chu and Hablitz, 1998). mGluR5 knock-out mice fail to selfadminister cocaine and do not display cocaine-induced increases in locomotor activity, effects that are paralleled by the selective mGluR5 antagonist 2-methyl-6(phenylethynyl)-pyridine (Chiamulera et al., 2001; McGeehan et al., 2004). Hence, the induction by cocaine of $\mathrm{GABA}_{\mathrm{A}}$ receptor subunits, substance $\mathrm{P}$, and mGluR5, achieved via $\Delta \mathrm{FosB}$, would be expected to inhibit OFC function and mediate some of the behavioral adaptations demonstrated in this study.

Not all cocaine users become addicts, and the development of tolerance and sensitization to the rewarding and detrimental effects of the drug may reflect vulnerability to addiction (Robinson and Berridge, 1993; Kosten et al., 1998; Kalivas and Volkow, 2005). Users who experience tolerance to the deleterious effects of cocaine are more likely to become cocaine dependent, whereas those who find the drug more disruptive at work or school are less likely to become addicted (Shaffer and Eber, 2002). Tolerance to the cognitive disruption caused by acute cocaine in cocaineexperienced individuals may therefore facilitate the maintenance of addiction. In this way, $\Delta$ FosB induction in the OFC may promote an addicted state, similar to its actions in the nucleus accumbens in which $\Delta$ FosB promotes addiction by enhancing the rewarding and incentive motivational effects of the drug (Kelz et al., 1999; Colby et al., 2003). Understanding the actions of cocaine, and of $\triangle F o s B$, in the OFC could provide valuable insight into the nature of addiction and stimulate the development of novel treatment strategies to combat addictive disorders.

\section{References}

Adinoff B, Devous MD, Sr., Best SM, George MS, Alexander D, Payne K (2001) Limbic responsiveness to procaine in cocaine-addicted subjects. Am J Psychiatry 158:390-398.

Bachtell RK, Whisler K, Karanian D, SelfDW (2005) Effects of intra-nucleus accumbens shell administration of dopamine agonists and antagonists on cocaine-taking and cocaine-seeking behaviors in the rat. Psychopharmacology (Berl) 183:41-53

Balleine BW, Dickinson A (1998) Goal-directed instrumental action: con- 
tingency and incentive learning and their cortical substrates. Neuropharmacology 37:407-419.

Bardo MT, Rowlett JK, Harris MJ (1995) Conditioned place preference using opiate and stimulant drugs: a meta-analysis. Neurosci Biobehav Rev 19:39-51.

Bechara A, Damasio H (2002) Decision-making and addiction (part I): impaired activation of somatic states in substance dependent individuals when pondering decisions with negative future consequences. Neuropsychologia 40:1675-1689.

Bechara A, Damasio H, Damasio AR, Lee GP (1999) Different contributions of the human amygdala and ventromedial prefrontal cortex to decisionmaking. J Neurosci 19:5473-5481.

Berton O, McClung CA, Dileone RJ, Krishnan V, Renthal W, Russo SJ, Graham D, Tsankova NM, Bolanos CA, Rios M, Monteggia LM, Self DW, Nestler EJ (2006) Essential role of BDNF in the mesolimbic dopamine pathway in social defeat stress. Science 311:864-868.

Carli M, Robbins TW, Evenden JL, Everitt BJ (1983) Effects of lesions to ascending noradrenergic neurons on performance of a 5-choice serial reaction time task in rats: implications for theories of dorsal noradrenergic bundle function based on selective attention and arousal. Behav Brain Res 9:361-380.

Chiamulera C, Epping-Jordan MP, Zocchi A, Marcon C, Cottiny C, Tacconi S, Corsi M, Orzi F, Conquet F (2001) Reinforcing and locomotor stimulant effects of cocaine are absent in mGluR5 null mutant mice. Nat Neurosci 4:873-874.

Chu Z, Hablitz JJ (1998) Activation of group I mGluRs increases spontaneous IPSC frequency in rat frontal cortex. J Neurophysiol 80:621-627.

Chudasama Y, Passetti F, Rhodes SEV, Lopian D, Desai A, Robbins TW (2003) Dissociable aspects of performance on the 5 choice serial reaction time task following lesions of the dorsal anterior cingulate, infralimbic and orbitofrontal cortex in the rat: differential effects on selectivity, impulsivity and compulsivity. Behav Brain Res 146:105-119.

Colby CR, Whisler K, Steffen C, Nestler EJ, Self DW (2003) Striatal cell type-specific overexpression of $\Delta \mathrm{FosB}$ enhances incentive for cocaine. J Neurosci 23:2488-2493.

Cole BJ, Robbins TW (1987) Amphetamine impairs the discriminative performance of rats with dorsal noradrenergic bundle lesions on a 5-choice serial reaction time task: new evidence for central dopaminergicnoradrenergic interactions. Psychopharmacology 91:458-466.

Dalley JW, Laane K, Pena Y, Theobald DE, Everitt BJ, Robbins TW (2005a) Attentional and motivational deficits in rats withdrawn from intravenous self-administration of cocaine or heroin. Psychopharmacology (Berl) 182:579-587.

Dalley JW, Theobald DEH, Berry D, Milstein JA, Laane K, Everitt BJ, Robbins TW (2005b) Cognitive sequalae of intravenous amphetamine selfadministration in rats: evidence for selective effects on attentional performance. Neuropsychopharmacology 30:525-537.

Dunn E, Fritschy JM, Carter DB, Merchant KM (1996) Differential distribution of gamma-aminobutyric acidA receptor subunit (alpha 1, alpha 2, alpha 3 , alpha 5 and beta $2+3$ ) immunoreactivity in the medial prefrontal cortex of the rat. Neurosci Lett 210:213-217.

Ersche KD, Fletcher PC, Lewis SJ, Clark L, Stocks-Gee G, London M, Deakin JB, Robbins TW, Sahakian BJ (2005) Abnormal frontal activations related to decision-making in current and former amphetamine and opiate dependent individuals. Psychopharmacology (Berl) 180:612-623.

Ersche KD, Fletcher PC, Roiser JP, Fryer TD, London M, Robbins TW, Sahakian BJ (2006) Differences in orbitofrontal activation during decisionmaking between methadone-maintained opiate users, heroin users and healthy volunteers. Psychopharmacology (Berl) 188:364-373.

Evenden JL, Ryan CN (1996) The pharmacology of impulsive behaviour in rats: the effects of drugs on response choice with varying delays of reinforcement. Psychopharmacology 128:161-170.

Everitt BJ, Robbins TW (2005) Neural systems of reinforcement for drug addiction: from actions to habits to compulsion. Nat Neurosci 8:1481-1489.

Guo L, Lobenhofer EK, Wang C, Shippy R, Harris SC, Zhang L, Mei N, Chen T, Herman D, Goodsaid FM, Hurban P, Phillips KL, Xu J, Deng X, Sun YA, Tong W, Dragan YP, Shi L (2006) Rat toxicogenomic study reveals analytical consistency across microarray platforms. Nat Biotechnol 24:1162-1169.

Hommel JD, Sears RM, Georgescu D, Simmons DL, DiLeone RJ (2003) Lo- cal gene knockdown in the brain using viral-mediated RNA interference. Nat Med 9:1539-1544.

Hopper JW, Karlsgodt KH, Adler CM, Macklin EA, Lukas SE, Elman I (2004) Effects of acute cortisol and cocaine administration on attention, recall and recognition task performance in individuals with cocaine dependence. Hum Psychopharmacol 19:511-516.

Huang CC, Lin HJ, Hsu KS (2006) Repeated cocaine administration promotes long-term potentiation induction in rat medial prefrontal cortex. Cereb Cortex 17:1877-1888.

Hutcheson DM, Everitt BJ (2003) The effects of selective orbitofrontal cortex lesions on the acquisition and performance of cue-controlled cocaine seeking in rats. Ann NY Acad Sci 1003:410-411.

Jentsch JD, Taylor JR (1999) Impulsivity resulting from frontostriatal dysfunction in drug abuse: implications for the control of behavior by reward-related stimuli. Psychopharmacology 146:373-390.

Johnson BA, Roache JD, Ait-Daoud N, Wallace CL, Wells LT, Wang Y, Dawes MA (2005) Effects of isradipine on cocaine-induced changes in cognitive performance in recently abstinent cocaine-dependent individuals. Int J Neuropsychopharmacol 8:549-556.

Kalivas PW, Volkow ND (2005) The neural basis of addiction: a pathology of motivation and choice. Am J Psychiatry 162:1403-1413.

Kelz MB, Chen J, Carlezon Jr WA, Whisler K, Gilden L, Beckmann AM, Steffen C, Zhang YJ, Marotti L, Self DW, Tkatch T, Baranauskas G, Surmeier DJ, Neve RL, Duman RS, Picciotto MR, Nestler EJ (1999) Expression of the transcription factor deltaFosB in the brain controls sensitivity to cocaine. Nature 401:272-276.

Kosten TR, Markou A, Koob GF (1998) Depression and stimulant dependence: neurobiology and pharmacotherapy. J Nerv Ment Dis 186:737-745.

Krawczyk DC (2002) Contributions of the prefrontal cortex to the neural basis of human decision making. Neurosci Biobehav Rev 26:631-664.

MAQC Consortium (2006) The Microarray Quality Control (MAQC) project shows inter- and intraplatform reproducibility of gene expression measurement. Nature Biotechnol 24:1151-1161.

Maubach KA, Cody C, Jones RS (1998) Tachykinins may modify spontaneous epileptiform activity in the rat entorhinal cortex in vitro by activating GABAergic inhibition. Neuroscience 83:1047-1062.

McClung CA, Nestler EJ (2003) Regulation of gene expression and cocaine reward by CREB and DeltaFosB. Nat Neurosci 6:1208-1215.

McClung CA, Nestler EJ, Zachariou V (2005) Regulation of gene expression by chronic morphine and morphine withdrawal in the locus ceruleus and ventral tegmental area. J Neurosci 25:6005-6015.

McGeehan AJ, Janak PH, Olive MF (2004) Effect of the mGluR5 antagonist 6-methyl-2-(phenylethynyl)pyridine (MPEP) on the acute locomotor stimulant properties of cocaine, D-amphetamine, and the dopamine reuptake inhibitor GBR12909 in mice. Psychopharmacology (Berl) 174:266-273.

Nestler EJ, Barrot M, Self DW (2001) DeltaFosB: a sustained molecular switch for addiction. Proc Natl Acad Sci USA 98:11042-11046.

Nye HE, Hope BT, Kelz MB, Iadarola M, Nestler EJ (1995) Pharmacological studies of the regulation of chronic FOS-related antigen induction by cocaine in the striatum and nucleus accumbens. J Pharmacol Exp Ther 275:1671-1680.

Peakman MC, Colby C, Perrotti LI, Tekumalla P, Carle T, Ulery P, Chao J, Duman C, Steffen C, Monteggia L, Allen MR, Stock JL, Duman RS, McNeish JD, Barrot M, Self DW, Nestler EJ, Schaeffer E (2003) Inducible, brain region-specific expression of a dominant negative mutant of c-Jun in transgenic mice decreases sensitivity to cocaine. Brain Res 970:73-86.

Peng X, Wood CL, Blalock EM, Chen KC, Landfield PW, Stromberg AJ (2003) Statistical implications of pooling RNA samples for microarray experiments. BMC Bioinformatics 4:26.

Penny GR, Afsharpour S, Kitai ST (1986) Substance P-immunoreactive neurons in the neocortex of the rat: a subset of the glutamic acid decarboxylase-immunoreactive neurons. Neurosci Lett 65:53-59.

Perrotti LI, Hadeishi Y, Ulery PG, Barrot M, Monteggia L, Duman RS, Nestler EJ (2004) Induction of $\Delta$ FosB in reward-related brain structures after chronic stress. J Neurosci 24:10594-10602.

Porrino LJ, Lyons D, Miller MD, Smith HR, Friedman DP, Daunais JB, Nader MA (2002) Metabolic mapping of the effects of cocaine during the initial phases of self-administration in the nonhuman primate. J Neurosci 22:7687-7694.

Powell KJ, Binder TL, Hori S, Nakabeppu Y, Weinberger DR, Lipska BK, 
Robertson GS (2006) Neonatal ventral hippocampal lesions produce an elevation of DeltaFosB-like protein (s) in the rodent neocortex. Neuropsychopharmacology 31:700-711.

Robinson TE, Berridge KC (1993) The neural basis of drug craving: an incentive-sensitization theory of addiction. Brain Res Brain Res Rev 18:247-291.

Rogers RD, Robbins TW (2001) Investigating the neurocognitive deficits associated with chronic drug misuse. Curr Opin Neurobiol 11:250-257.

Rolls ET (2006) Brain mechanisms underlying flavour and appetite. Philos Trans R Soc Lond B Biol Sci 361:1123-1136.

Saffroy M, Torrens Y, Glowinski J, Beaujouan JC (2003) Autoradiographic distribution of tachykinin NK2 binding sites in the rat brain: comparison with NK1 and NK3 binding sites. Neuroscience 116:761-773.

Schoenbaum G, Chiba AA, Gallagher M (1999) Neural encoding in orbitofrontal cortex and basolateral amygdala during olfactory discrimination learning. J Neurosci 19:1876-1884.

Schoenbaum G, Saddoris MP, Ramus SJ, Shaham Y, Setlow B (2004) Cocaine-experienced rats exhibit learning deficits in a task sensitive to orbitofrontal cortex lesions. Eur J Neurosci 19:1997-2002.

Schoenbaum G, Roesch MR, Stalnaker TA (2006) Orbitofrontal cortex, decision-making and drug addiction. Trends Neurosci 29:116-124.

Shaffer HJ, Eber GB (2002) Temporal progression of cocaine dependence symptoms in the US National Comorbidity Survey. Addiction 97:543-554.

Shoji S, Simms D, Yamada K, Gallagher JP (1998) Cocaine administered in vitro to brain slices from rats treated with cocaine chronically in vivo results in a gamma-aminobutyric acid receptor-mediated hyperpolarization recorded from the dorsolateral septum. J Pharmacol Exp Ther 286:509-518

Stacey AE, Woodhall GL, Jones RS (2002) Activation of neurokinin-1 receptors promotes GABA release at synapses in the rat entorhinal cortex. Neuroscience 115:575-586.

Volkow ND, Fowler JS (2000) Addiction, a disease of compulsion and drive: involvement of the orbitofrontal cortex. Cereb Cortex 10:318-325.

Wade TR, de Wit H, Richards JB (2000) Effects of dopaminergic drugs on delayed reward as a measure of impulsive behavior in rats. Psychopharmacology 150:90-101.

Weissenborn R, Robbins TW, Everitt BJ (1997) Effects of medial prefrontal or anterior cingulate cortex lesions on responding for cocaine under fixed-ratio and second-order schedules of reinforcement in rats. Psychopharmacology (Berl) 134:242-257.

Winstanley CA, Theobald DE, Dalley JW, Robbins TW (2003) Global 5-HT depletion attenuates the ability of amphetamine to decrease impulsive choice in rats. Psychopharmacology 170:320-331.

Winstanley CA, Theobald DE, Cardinal RN, Robbins TW (2004) Contrasting roles for basolateral amygdala and orbitofrontal cortex in impulsive choice. J Neurosci 24:4718-4722.

Zachariou V, Bolanos CA, Selley DE, Theobald D, Cassidy MP, Kelz MB, Shaw-Lutchman T, Berton O, Sim-Selley LJ, Dileone RJ, Kumar A, Nestler EJ (2006) An essential role for DeltaFosB in the nucleus accumbens in morphine action. Nat Neurosci 9:205-211. 